\title{
Epidemiology of Mental Health and Mental Health Issues of Women in India: A Literature Review
}

\author{
Amit Das ${ }^{1 *}$
}

\section{ABSTRACT}

Worldwide 450 million (12\%) people suffer from disability and this will be increased up to 15\% in the year 2020, as per WHO estimation. Psychiatric Epidemiological studies in India from 1964 to 2001, shows increasing trends of mental health morbidity prevalence from 9.5 to 102.8 per 1000 population and new incidence cases were over 16.0 per 1000 population. A study reported that overall life time prevalence of mental disorder to be around 5\%. Depression, anxiety, and unspecified psychological distress are 2-3 times more common among women compare to men. Common Mental Disorders is common among poor women and the causes may be hormonal factors (reproductive cycle may play a role of increased vulnerability to depression), other factors are excessive partner, alcohol use, sexual, physical violence by the husband, being widowed or separated, having low autonomy in decision making, and low levels of support from one's family. Illiteracy and women mental health is significantly associated in India. Suicide and rape also related to mental health issues in Indian women. In 2012, National Crime Records Bureau reported 24,923 rape cases and among them $98 \%$ being committed by someone known to victims. Studies found that girls from nuclear families and women married at a very young age are in higher risk for committing suicide. To reduce these problems, Indian Constitution made several articles and acts to safeguard the disabilities/issues including women. Several NGO's and VO's are also working for the development of this section.

\section{Keywords: Epidemiology, Mental Health}

The World Health Organization's Ottawa Charter for Health Promotion in 1986, sees health as multidimensional and espouses a social model of health. It defines health as 'a positive concept emphasizing social and personal resources, as well as physical capacities (World Health Organization, 1986).

\footnotetext{
${ }^{1}$ Research Scholar, Department of Social Work, Assam University, Silchar, Assam, India *Responding Author

Received: January 29, 2017; Revision Received: February 15, 2017; Accepted: February 24, 2017

(C) 2017 Das A; licensee IJIP. This is an Open Access Research distributed under the terms of the Creative Commons Attribution License (www.creativecommons.org/licenses/by/2.0), which permits unrestricted use, distribution, and reproduction in any Medium, provided the original work is properly cited.
} 
WHO report on the social dimensions of mental health, which states that: 'Mental health is the capacity of the individual, the group and the environment to interact with one another in ways that promote subjective well-being, the optimal development and use of mental abilities involves cognitive, affective and relational, the achievement of individual and collective goals consistent with justice and the attainment and preservation of conditions of fundamental equality (World Health Organization, 1981). This definition does not mention gender, but gender can and does impact on the production of mental health at every level - the individual, the group and the environment- and is critically implicated in the differential delivery of justice and equality. Gender configures both the material and symbolic position women occupy in the social hierarchy as well as the experiences which condition their lives.

Women and men differ in the way they communicate, deal in relationships, express their feelings, and react to stress. Thus, the gender differences are based in physical, physiological, and psychological attributes. There are psychological theories that present a gender sensitive viewpoint called as alpha bias, and there are others that are gender neutral representing beta bias. Alpha bias proposes that men and women are different and opposite, and in beta bias differences between men and women are ignored. Alpha bias is seen in psychodynamic theories and therapies where according to Freudian viewpoint, male anatomy and masculinity is the most desired and cherished goal and female anatomy and femininity are seen as a deviation. In contrast, the cognitive theories, behavioral theories, and humanistic-existential theories have beta bias (Hare-Mustin and Marecek, 1988). It is necessary to understand and accept that women and men differ in biological attributes, needs, and vulnerabilities.

The importance of gender differences in mental health is most graphically illustrated in the significantly different rates of major depression experienced by women compared with men. A recent comprehensive review, Gender Differences in the Epidemiology of Affective Disorders and Schizophrenia, found that women predominated over men in lifetime prevalence rates of major depression in all the general population studies conducted so far (Piccinelli and Homen, 1997).

Beginning with the Second World War, epidemiology has grown by leaps and bounds all over the world, even though gross disparities are noticed even today, both between and within countries in its development and application. This branch of community and clinical medicine, means literally 'on the people', indicating study of populations. Epidemiology as a branch of public health has also grown in principles, methods and applications over a period of time (Park, 2002). Epidemiology is defined as 'the study of distribution and determinants of health-related states or events in specified populations, and the application of this study to the control of health problems' (Last, 1988). Psychiatric epidemiology is the study of the distribution and determinants of mental illness frequency in human beings, with the fundamental aim of understanding and controlling the occurrence of mental illness. Psychiatric epidemiology deals 
Epidemiology of Mental Health and Mental Health Issues of Women in India: A Literature Review

with important components such as disease/disorder, distribution and frequency of disease/disorder, determinants of disease/disorder, human population and methods employed to control the occurrence of illness (Aschengrau and Seage, 2003).

\section{METHODS}

Secondary data collection method was followed for this review study. The authors searched articles and reports from several journals which were published in PubMed, Google Scholar, CrossRef, Google, etc. from the year 1964 to 2012. The authors accepted both published and unpublished works. Out of 86 searched publications, a total 49 articles were included for this review. The search engine consists of both research papers and review papers.

\section{RESULTS AND DISCUSSION}

\section{Epidemiological studies of mental health in India}

WHO estimated that globally over 450 million people suffer from mental disorders and currently mental and behavioral disorders account for about 12 percent of the global burden of diseases. This is likely to increase to 15 percent by 2020. Major proportions of mental disorders come from low and middle income countries (World Health Organization, 2001). So, globally the issues of mental health considered one of the health issues that people suffers. Descriptive epidemiological studies have provided data about the prevalence of mental disorders in the community. However, many researchers have expressed reservations about the comparison of various epidemiological studies because of methodological differences. Varying prevalence rates have been reported in international studies like the Epidemiological Catchment Area Program and the National Co-morbidity Survey (Regier et al., 1998, Murphy et al., 2000).

Psychiatric epidemiology has kept its place with the general growth of psychiatric research in India. (Wig and Akhtar, 1974) mentioned that psychiatric research itself has grown by leaps and bounds in India since the time of independence. Wig clearly classifies this during the periods 1947-1960 (a slow phase of growth due to the lack of researchers and clarity issues) and 19601972 (a period of psychiatric epidemiological surveys and some focused studies). (Kessler, 1999) expressed about global developments of psychiatric epidemiology. (Murthy, 1987) mentioned that, India has not lagged behind in the growth of psychiatric epidemiology.

Epidemiological studies divided into several types i.e., prevalence study, incidence study, and follow up study. Prevalence studies can be simply defined as total number of persons in the population who have disease/problems at a point or period in time. It refers to both old and new cases. If the observational period is at a given point in time it is called as 'point prevalence' and if it is at a given specific period in time it is called as 'period prevalence'(Park, 2007). Most of the community-based Indian epidemiological studies are on point prevalence which summarizes the prevalence of psychiatric morbidity in the general population. These community-based 
epidemiological studies (Table 1) conducted in India on mental and behavioral disorders report varying prevalence rates, ranging from 9.5 to 102.8 per 1000 population.

Table 1: Prevalence of psychiatric morbidity and incidences from Indian Epidemiological studies

\begin{tabular}{|c|c|c|c|c|c|c|}
\hline Investigator/s & Centre & $\begin{array}{l}\text { Samplin } \\
\text { g }\end{array}$ & Tool used & $\begin{array}{l}\text { Populati } \\
\text { on }\end{array}$ & $\begin{array}{l}\text { Prevale } \\
\text { n-ce per } \\
1000\end{array}$ & $\begin{array}{l}\text { Incide } \\
\text { n-ce } \\
\text { per } \\
1000\end{array}$ \\
\hline Surya, 1964 & Pondicherry & $\mathrm{H}-\mathrm{H}$ & MHSQ(P) & 2731 & 9.5 & \\
\hline Dube, 1970 & Agra & $\mathrm{H}-\mathrm{H}$ & DCP & 29,468 & 18.0 & \\
\hline Elnager et al, 1971 & Hoogly & $\mathrm{H}-\mathrm{H}$ & CHM and DCP(2) & 1393 & 27.0 & \\
\hline Sethi et al, 1972 & Lucknow & $\mathrm{H}-\mathrm{H}$ & CHQ and CHM & 2691 & 39.4 & \\
\hline Verghese et al., 1973 & Vellore & SRS & MHIS and DCP & 1887 & 66.5 & \\
\hline Sethi et al, 1974 & Lucknow & 3SPS & PSQ and DCP & 4481 & 67 & \\
\hline Thacore et al., 1975 & Lucknow & $\mathrm{H}-\mathrm{H}$ & PHQ and DCP & 1977 & 81.6 & \\
\hline Nandi et al., 1975 & $\begin{array}{l}\text { West } \\
\text { Bengal }\end{array}$ & $\mathrm{H}-\mathrm{H}$ & HS, QS and CRS & 1060 & 102.8 & \\
\hline Nandi et al.,2000 & $\begin{array}{l}\text { West } \\
\text { Bengal }\end{array}$ & $\mathrm{H}-\mathrm{H}$ & HS, QS and CDS & 1060 & & 17.6 \\
\hline Nandi et al., 1976 & $\begin{array}{l}\text { West } \\
\text { Bengal }\end{array}$ & $\mathrm{H}-\mathrm{H}$ & HS, CDS and CRS & 2230 & & 16 \\
\hline Nandi et al., 1979 & $\begin{array}{l}\text { West } \\
\text { Bengal }\end{array}$ & $\mathrm{H}-\mathrm{H}$ & $\begin{array}{l}\text { HS, SESS, CDS, \& } \\
\text { CRS }\end{array}$ & 3718 & 102 & \\
\hline Shah et al., 1980 & Ahmedabad & $\mathrm{H}-\mathrm{H}$ & MHSQ and DCP & 2712 & 47.2 & \\
\hline Mehta et al., 1985 & Vellore & S-S & IPSS and DCP & 5941 & 14.5 & \\
\hline Sachdeva et al., 1986 & Faridkot & $\mathrm{H}-\mathrm{H}$ & HS, SESS and CDS & 1989 & 22.12 & \\
\hline $\begin{array}{l}\begin{array}{l}\text { Premrajan et al., } \\
1993\end{array} \\
\end{array}$ & Pondicherry & RS & IPSS and DCP & 1115 & 99.4 & \\
\hline Shaji et al., 1995 & Erankulam & $\mathrm{H}-\mathrm{H}$ & $\begin{array}{l}\text { IPSS, SESS, CRS \& } \\
\text { DCP }\end{array}$ & 5284 & 14.57 & \\
\hline $\begin{array}{l}\text { Sharma and Singh, } \\
2001\end{array}$ & Goa & SRS & RPES and DCP & 4022 & 60.2 & \\
\hline
\end{tabular}

Abbreviation - H-H - House to house survey, S-S - Systematic sampling, SRS - stratified random sampling, 3SPS - 3-stage probability sampling, RS - random sampling, ICD - International classification of diseases, DSM-II - diagnostic and statistical manual of mental disorders. Tools: MHSQ = Mental health screening questionnaire, DCP = Diagnosis confirmed by a psychiatrist (S), CHM = Case history method, $C H Q=$ Case history questionnaire, IPSS = Indian Psychiatric survey schedule, SFQ $=$ Social functioning questionnaire, MHIS = Mental health item sheet, $P S Q=$ Psychiatric screening questionnaire, $P H Q=$ Psychiatric health questionnaire, $H S=$ Household schedule, $Q S=$ Questionnaire schedule, CRS $=$ Case record schedule, $C D S=$ Case detection schedule, $S E S S=$ Socioeconomic status schedule, RPES = Rapid psychiatric examination schedule

Source: Math et al., 2007

A study conducted in Pune in 2012 reported the overall life time prevalence of mental disorders to be nearly 5 percent (Deswal and Pawar, 2012). Only two studies conducted on incidence which shows that the incidence was over 16 per 1000 population. In India, less numbers of incidence studies conducted and the result shows an increasing trend compare to WHO 


\section{Epidemiology of Mental Health and Mental Health Issues of Women in India: A Literature Review}

prediction of 2020. India is a developing country and increasing trend of mental health disorders/issues may lead its health and economy.

\section{Understanding mental health issues and disorders in India}

Worldwide, gender is a critical determinant of mental health and mental illness. Symptoms of depression, anxiety, and unspecified psychological distress are 2-3 times more common among women compare to men (World Health Organization, 2001). From the various literature reviews it has found that majority of women in India, during their life-span faces several problems like domestic violence, particularly spousal violence, dowry related stressors, and poor family support.

Females are more predisposed to mental disorders due to rapid social change, gender discrimination, social exclusion, gender disadvantage like marrying at young age, concern about the husband's substance misuse habits, and domestic violence (Patel and Kleinman, 2003). Poorer women are more likely to suffer from adverse life events, to live in crowded or stressful conditions, to have fewer occupational opportunities and to have chronic illnesses; all of these are recognized risk factors for common mental disorders (Kermode et al., 2007). A study on National Literacy Mission in Northern India shows there is an association between female illiteracy and poor mental health (Cohen, 2002). Community-based studies and studies of treatment seekers in India indicate that women are on average, 2-3 times, at greater risk to be affected by common mental disorder (Thara and Patel, 2001). This may be due to hormonal factors related to the reproductive cycle may play a role in women's increased vulnerability to depression (Parry, 2000). Another factor may be include excessive partner alcohol use, sexual, and physical violence by the husband, being widowed or separated, having low autonomy in decision making, and having low levels of support from one's family (Patel et al., 2006, Shidhaye and Patel, 2010, Nayak et al., 2010). There are a number of potential factors, which increase vulnerability of women to common mental disorder. The reproductive roles of women, such as her expected role of bearing children, the consequences of infertility and the failure to produce a male child, have been linked to wife battering and female suicide (Davar, 1999, Dennerstein et al., 1993). Suicide is another serious mental health problem of women in India. The common causes for suicide in India are disturbed interpersonal relationships followed by psychiatric disorders and physical illness (Rao, 2004). A study found that girls from nuclear families and women married at a very young age, to be at a higher risk for attempted suicide and self-harm (Biswas et al., 1997). Indian women are also facing the problems of rape and it is the fourth most common crime in India against women (Kumar, 1993). National Crime Records Bureau, 2012, reported that in India there were 24,923 rape cases in the year 2012, and among them $98 \%$ being committed by someone known to the victim.

Indian constitution made several articles and acts to deal with such disabilities from our society and these were implemented in national, state, district, and block levels. Several non-

(c) The International Journal of Indian Psychology, ISSN 2348-5396 (e) | ISSN: 2349-3429 (p) | 9 
governmental organizations (NGOs) and voluntary organizations (VOs) in India are also working for the development of women and their associated mental disorders/issues.

\section{CONCLUSION}

Epidemiology of mental health in India shows that there is an increasing trend of mental health morbidities from 9.5 to 102.8 per 1000 persons. Generally women were facing issues of common mental disorders (CMD) which includes depression, anxiety, domestic violence, suicide, rape, etc. These types of disorders/issues female have 2-3 times more compare to males. So, these are the matter of concern and accordingly for preventive measures Indian constitution made several articles and acts. Apart from this several NGOs and VOs are working and also need to work for the development of women in respect of problems of their mental disorders/issues.

\section{Acknowledgments}

The author appreciates all those who participated in the study and helped to facilitate the research process.

Conflict of Interests: The author declared no conflict of interests.

\section{REFERENCES}

Aschengrau, A., \& Seage, G. R. (2003). Essentials of epidemiology in public health. 3rd (ed). Pub: Jones and Bartlett, Sudbury, Massachusetts.

Biswas, S., Roy, S., Debnath, C., \& Sengupta, S. B. (1997). A study of attempted suicide in adolescents in West Bengal. Indian Journal Of Psychiatry, 39, 54 - 55.

Cohen, A. (2002). Our lives were covered in darkness. In: Cohen A, Kleinman A, Saraceno B, eds. The Work of the National Literacy Mission in Northern India, Chapter 5, World Mental Health Case Book. New York: Kluwer Academic/Plenum Publishers.

Crime in India. (2012). Statistics. National Crimes Record Bureau, Ministry of Home Affairs, Government of India. Available from website: http://www.ncrb.nic.in/CDCII2012/Statistics2012.pdf. Retrieved on 12/12/2016.

Davar, B. (1999). The Mental Health of Indian Women: A Feminist Agenda. New Delhi: Sage publication.

Dennerstein, L., Astbury, J., \& Morse, C. (1993). Psychosocial and Mental Health Aspects of Women's Health. WHO/FHE/ MNH/93.1. Geneva: World Health Organization.

Deswal, B. S., \& Pawar, A. (2012). An Epidemiological Study of Mental Disorders at Pune, Maharashtra. Indian J Community Med, 37(2), 116 - 121.

Dube, K. C. (1970). A Study of prevalence and biosocial variables in mental illness in rural and urban community in Uttar Pradesh, India. Acta Psychiatr Scand, 46, 327 - 359.

Elnager, M. N., Maitra, P., \& Rao, M. N. (1971). Mental health in an Indian rural community. $\mathrm{Br}$ J Psychiatry, 118, 499 - 503.

Geneva: World Health Organization. (2001). World Health Organization. Gender and women's mental health. Gender disparities and mental health: The Facts.

Hare-Mustin, R. T., \& Marecek, J. (1988). The meaning of difference. Gender theory, postmodernism and psychology. Am Psychol, 43, 455-64. 
Epidemiology of Mental Health and Mental Health Issues of Women in India: A Literature Review

Kermode, M., Herrman, H., Arole, R., White, J., Premkumar, R., \& Patel, V. (2007). Empowerment of women and mental health promotion: a qualitative study in rural Maharashtra, India. BMC Public Health, 7, 225.

Kessler, R. C. (1999). The World Health Organization International Consortium in Psychiatric Epidemiology (ICPE): Initial work and future directions — The Nape Lecture 1998a. Acta Psychiatrica Scandinavica, 99, 2 - 9.

Kumar, R. (1993). The History of Doing: An Account of Women's Rights and Feminism in India. Zubaan, 128.

Last, J. M. (1988). A Dictionary of Epidemiology, 2nd (ed). New York: Oxford University Press.

Math, S. B., Chandrashekar, C. R., \& Bhugra D. (2007). Psychiatric epidemiology in India. Indian J Med Res, 126, $183-192$.

Mehta, P., Joseph, A., \& Verghese, A. (1985). An epidemiological study of psychiatric disorders in a rural area in Tamil Nadu. Indian J Psychiatry, 27, 153 - 158.

Murphy, J. M., Monson, R. R., Laird, N. M., Sobol, A. M., \& Leighton, A. H. (2000). A comparison of diagnostic interviews for depression in the Stirling County study: Challenges for psychiatric epidemiology. Arch Gen Psychiatry, 57, 230 - 236.

Murthy, R. S. (1987). Overview of Psychiatric Epidemiology in India (unpublished). Workshop on research issues in psychiatric epidemiology in India.

Nandi, D. N., Ajmany, S., Ganguli, H., Banerjee, G., Boral, G. C., \& Sarkar, S. (1976). The incidence of mental disorders in one year community in West Bengal. Indian $J$ Psychiatry, 18, 79 - 87.

Nandi, D. N., Ajmany, S., Ganguly, H., Banerjee, G., Boral, G. C., Ghosh, A., et al. (1975). Psychiatric disorders in a rural community in West Bengal: An epidemiological study. Indian J Psychiatry, 17, 87 - 99.

Nandi, D. N., Banerjee, G., Boral, G. C., Ganguli, H., Ajmany, S., Ghosh, A., et al. (1979). Socio-economic status and prevalence of mental disorders in certain rural communities in India. Acta Psychiatr Scand, 59, 276 - 293.

Nandi, D. N., Banerjee, G., Mukherjee, S. P., Ghosh, A., Nandi, P. S., \& Nandi, S. (2000). Psychiatric morbidity of a rural Indian community: Changes over a 20-year interval. $\mathrm{Br} \mathrm{J}$ Psychiatry, 176, $351-356$.

Nayak, M. B., Patel, V., Bond, J. C., \& Greenfield, T. K. (2010). Partner alcohol use, violence and women's mental health: Population-based survey in India. Br J Psychiatry, 196, 192 $-199$.

Park, K. (2002). Park's Textbook of Preventive \& Social Medicine. 17th (ed). Jabalpur: Banarsidas Bhanot.

Park, K. (2007). Park's Textbook of Preventive \& Social Medicine. 19th (ed). Jabalpur: Banarsidas Bhanot.

Parry, B. L. (2000). Hormonal basis of mood disorders in women. In: Frank E, editor. Gender and Its Effects on Psychopathology. Washington DC: American Psychiatric Press, 61-84.

Patel, V., \& Kleinman, A. (2003). Poverty and common mental disorders in developing countries. Bull World Health Organ, 81(8), 609 - 615.

Patel, V., Kirkwood, B. R., Pednekar, S., Pereira, B., Barros, P., Fernandes, J., et al. (2006). Gender disadvantage and reproductive health risk factors for common mental disorders in women: A community survey in India. Arch Gen Psychiatry, 63, 404 - 413.

Piccinelli, M., \& Homen, F. G. (1997). Gender differences in the epidemiology of affective disorders and schizophrenia. Geneva: World Health Organization. 
Premrajan, K. C., Danabalan, M., Chandrasekhar, R., \& Srinivasa, D. K. (1993). Prevalence of psychiatric morbidity in an urban community of Pondicherry. Indian J Psychiatry, 35, 99 $-102$.

Rao, V. (2004). Suicidology: The Indian context. In: Agarwal SP, editor. Mental Health: An Indian Perspective 1946-2003. New Delhi: Directorate General of Health Services/Ministry of Health and Family Welfare Nirman Bhawan, 279 - 284.

Regier, D. A, Kaelber, C. T., Rae, D. S., Farmer, M. E., Knauper, B., Kessler, R. C., et al. (1998). Limitations of diagnostic criteria and assessment instruments for mental disorders: Implications for research and policy. Arch Gen Psychiatry, 55, 109 - 115.

Sachdeva, J. S., Singh, S., Sidhu, B. S., Goyal, R. K. D., \& Singh, J. (1986). An epidemiological study of psychiatric disorders in rural Faridkot (Punjab). Indian J Psychiatry, 28, 317 - 323.

Sethi, B. B, Gupta, S. C., Mahendru, R. K., \& Kumari, P. (1972). A psychiatric survey of 500 rural families. Indian J Psychiatry, 14, 183 - 196.

Sethi, B. B., Gupta, S. C., Mahendru, R. K., \& Kumari, P. (1974). Mental Health and urban life: A study of 850 families. Br J Psychiatry, 124, $243-246$.

Shah, A. V., Goswami, U. A., Maniar, R. C., Hariwala, D. C., \& Sinha, B. K. (1980). Prevalence of psychiatric disorders in Ahmedabad: An epidemiological study. Indian J Psychiatry, 22, $384-388$.

Shaji. S., Verghese, A., Promodu, K., George, B., \& Shibu, V. P. (1995). Prevalence of priority psychiatric disorders in a rural area of Kerala. Indian J Psychiatry, 37, 91 - 96.

Sharma, S., \& Singh, M. M. (2001). Prevalence of mental disorders: An epidemiological study In Goa. Indian J Psychiatry, 43, 118 - 126.

Shidhaye, R., \& Patel, V. (2010). Association of socio-economic, gender and health factors with common mental disorders in women: A population-based study of 5703 married rural women in India. Int J Epidemiol, 39, 1510 - 1521.

Surya, N. C. (1964). Mental morbidity in Pondicherry. Transaction-4, Bangalore: All India Institute of Mental Health.

Thacore, V. R., Gupta, S. C., \& Suriya, M. (1975). Psychiatric Morbidity in North Indian Community. Br J Psychiatry, 126, 364 - 369.

Thara, R., \& Patel, V. (2001). Women's mental health: A public health concern. Regional Health Forum-WHO South-East Asia Region, 5, 24-34.

Verghese, A., Beig, A., Senseman, L. A., Sundar Rao, P. S., \& Benjamin, V. (1973). A social and psychiatric study of a representative group of families in Vellore town. Indian J Med Res, 61, $608-620$.

Wig, N. N., \& Akhtar, S. (1974). Twenty-five years of psychiatric research in India. Indian Journal of Psychiatry, 16, 48 - 64.

World Health Organization, Health and Welfare Canada. (1986). Ottawa charter for health promotion Canadian Public Health Association. Retrieved on 14/12/2016.

World Health Organization. (1981). Social dimensions of mental health (5). Geneva.

World Health Organization. The world health report. (2001). Mental Health: New Understanding, New Hope. World Health Organization 2001, Geneva.

How to cite this article: Das A (2017), Epidemiology of Mental Health and Mental Health Issues of Women in India: A Literature Review, International Journal of Indian Psychology, Volume 4, Issue 2, No. 92, ISSN:2348-5396 (e), ISSN:2349-3429 (p), DIP:18.01.101/20170402, ISBN:978-1-365-78192-6

(C) The International Journal of Indian Psychology, ISSN 2348-5396 (e)| ISSN: 2349-3429 (p) | 12 